\title{
Genetic relationships between calving date, calving interval, age at first calving and type traits in beef cattle
}

\author{
J.P. Gutiérrez ${ }^{\mathrm{a}}$, I. Alvarez ${ }^{\mathrm{b}}$, I. Fernández ${ }^{\mathrm{b}}$, L.J. Royo ${ }^{\mathrm{b}}$, J. Díez $^{\mathrm{b}}$, F. Goyache ${ }^{\mathrm{b}, *}$ \\ ${ }^{a}$ Departamento de Producción Animal, Facultad de Veterinaria, Universidad Complutense, E-28040 Madrid, Spain \\ ${ }^{\mathrm{b}}$ SERIDA-CENSYRA-Somió, Calle Camino de los Claveles 604, E-33203 Gijón (Asturias), Spain
}

Received 11 December 2001; received in revised form 26 April 2002; accepted 8 May 2002

\begin{abstract}
In this paper the genetic relationships between major reproductive traits in beef cattle (Calving Date, Calving Interval and Age at First Calving) and type traits have been estimated to evaluate the usefulness of type classification in predicting reproductive performance in beef cattle. We estimated favourable genetic correlations between Calving Interval and type traits ranging from -0.027 to -0.297 . However, type traits and Calving Date appear to be genetically independent and the genetic relationships between Age at First Calving and type traits are, in general, non-favourable. Genetic correlations between type traits and Calving Date ranged from 0.0 to -0.125. Genetic correlations between Age at First Calving and Final Score, Body Depth and Tight Development were, respectively, 0.399, 0.445 and 0.447. Our results suggest that the possibility of using type classification to construct an index to improve reproductive performance is little. The more reliable possibility to build a possible selection index comprising type classification and reproductive performance would be based on Age at First Calving. Type classification at first calving could help to increase the information to select dams to stay on the farm in subsequent calvings on the basis of their expected performance.
\end{abstract}

(c) 2002 Elsevier Science B.V. All rights reserved.

Keywords: Cattle; Genetics; Heritability; Type traits; Reproductive traits

\section{Introduction}

Improvement in cattle has focused on productive traits. However, reproductive regularity as an indicator of fertility dramatically affects cattle productivity. In beef cattle, whatever the production system, breeding traits appear to be the most econ-

\footnotetext{
*Corresponding author. Tel.: +34-985-195303; fax: +34-985195310.

E-mail address: fgoyache@serida.org (F. Goyache).
}

omically important traits (Newman et al., 1992; MacNeil et al., 1994) and only a dramatic decrease in the market price for beef would affect the relative weighting of reproductive traits in relation to growth and carcass traits (Phocas et al., 1998). Hence, fertility should be included as part of the breeding goal, but the possibilities of actually using reproductive information as a selection tool for breeders are limited. Some fertility indicators such as calving interval (CI) or age at first calving (AFC) are obtained by recording organisations and used as 
indicators of fertility (Tonhati et al., 2000; Van der Westhuizen et al., 2000). However, a long time interval is needed to record data, and traits to be included in the breeding goal are not always the same across different production systems. In addition, it is generally accepted that heritability of reproductive traits is very low, ranging between 0.03 and 0.05 (Freeman, 1984). Thus, reproductive traits are not usually included in selection indices and their improvement is carried out by adjustment of management practices. However, Koots et al. (1994a) reported that mean heritabilities of reproductive traits in beef cattle are higher than in dairy cattle. It would lead to use this higher genetic variability including reproductive merit in beef cattle genetic improvement schemes.

No completely satisfactory measure of reproduction has been found. Reproductive recording is affected by the age structure of the herds and the prevailing environmental and management conditions (Rust and Groeneveld, 2001). Additionally, reproductive performance is a complex trait that has many components. It is possible to separate the female 'reproductive complex' into subsets that are both relatively easy to measure and have higher heritabilities to be used in genetic improvement. CI has traditionally been the predominant measure of reproduction during the productive life of the animal, particularly in dairy cattle (Rege and Famula, 1993). However, CI might not be the most desirable measure of fertility to include in a breeding objective in beef cattle. Cows with a shorter CI are often those whose first calves were born late. Selecting these animals or their offspring could result in indirect selection for a later age at puberty (Bourdon and Brinks, 1983). There seems to be a high correlation between the AFC and the age at subsequent calvings, as well as between the age at calving and the interval between subsequent calvings. In consequence, it would not be possible to compensate late first calving with short intervals between successive calvings (Michaux et al., 1987). Bourdon and Brinks (1983) have proposed the use of the calving date (CD) as a better measure of fertility in beef cattle. These authors, and other later (see Ponzoni, 1992), have defined $\mathrm{CD}$ as the day number in which the cow calved within the calving season. CD is conceptually the same than Days-to-calving (Meyer et al., 1990) which is defined as the interval in days between the first joining date for cows and subsequent calving. However, Calving date is more appropriate to analyse field data because of we do not need to record the first joining date. This is especially useful in semi-extensive or extensive systems, such as Asturiana de los Valles productive system, which are dependent on natural pastures. In addition, $\mathrm{CD}$ can be a better measure of fertility in beef cattle than CI because of its clearer economic significance and higher heritability (Bourdon and Brinks, 1983; Rust and Groeneveld, 2001). Heavier weaning weights are associated with earlier CD. Earlier calving dams tend to be more efficient because a greater proportion of their annual cycle is spent in a lactating mode, diluting maintenance costs as a fraction of the total costs (Marshall et al., 1990). Additionally, CD is a less biased method for evaluating reproductive performance than $\mathrm{CI}$, especially when cows are mated during a restricted breeding season (Bourdon and Brinks, 1983; MacGregor and Casey, 1999).

Since cattle breeders have long held the belief that type traits are good indirect indicators of cattle performance, morphological assessment is a common activity in most cattle improvement programs. In dairy cattle, the scientific literature has paid a great deal of attention to type traits because of their influence on productive or longevity traits (Meyer et al., 1987; Brotherstone, 1994; Vukasinovic et al., 1997; Larroque and Ducrocq, 1999). However, there is little information on the use of type traits in beef cattle. Type classification is difficult to carry out in beef cattle because of the usually extensive management conditions. Additionally, linear classification system is not widely used in beef cattle. The nonlinear type classifications score the deviation (positive or negative) from an 'optimum', measuring less phenotypic and genetic variation. Traits at the extremes of the biological (anatomical) observed variability could show the same low score, thus inducing a loss of biological relationships between traits (Vukasinovic et al., 1997; Goyache et al., 2001; Gutiérrez and Goyache, 2002). Recently, we estimated genetic parameters of type traits in the Asturiana de los Valles beef cattle breed (Gutiérrez and Goyache, 2002). In order to evaluate the usefulness of the type assessment system, we propose to 
ascertain the genetic correlations between type traits and reproductive traits. Type classification could be justified in beef cattle if moderate genetic correlations were found between type and reproductive traits and the former were found to be useful as early predictors of reproductive performance.

The aim of this paper is to estimate the genetic relationships between major reproductive traits in beef cattle (calving date, calving interval and age at first calving) and type traits using a sample of data from the Asturiana de los Valles breed to evaluate the usefulness of type classification in predicting reproductive performance in beef cattle.

\section{Material and methods}

The Asturiana de los Valles classification system involves 11 different type traits and a Final Score (FS). A detailed description of the morphological assessment system and a discussion of the genetic parameters affecting the different type traits can be found in Gutiérrez and Goyache (2002). We propose to ascertain the genetic correlations among type traits showing the highest heritability or easier biological interpretation and reproductive traits. Six single type traits and FS were selected for the current analysis: Breed characteristics (BC), scoring the animal's conformity to the breed standard; Size (S), scoring the animal's skeletal development; Body Depth (BD), scoring the chest and belly depth; Thigh Development (TD), scoring the degree of development of the muscular masses of the thigh; Legs Line (LL), scoring the adjustment to right angles of the fore and hind legs; and Udder Development (UD), scoring udder size. In a similar way as reported by Vukasinovic et al. (1997) in Brown Swiss cattle, type traits are scored as a distance from the 'optimum' for each trait according the age of the assessed animal. Traits are scored numerically on a desirability scale from sufficient (5) to excellent (9). The available data was comprised of type records of pedigree animals of the Asturiana de los Valles beef cattle breed obtained from 1993 to 1998 by four Asturiana de los Valles Breeders Association's (ASEAVA) expert classifiers within the Principado de Asturias' Regional Cattle Improvement Program.

Additionally, calving dates were also obtained from classified dams or from dams appearing in pedigree information on classified dams. The Asturiana de los Valles breed is exploited mainly under a veal production system. Farms are dependent on the use of season-dependent range pastures. Calvings are concentrated mostly in spring (two thirds), basically from March to May, and to a lesser extent in autumn (a third), essentially in September-October. Consequently, two calving seasons were defined: from January 1st to June 30th and from July 1 st to December 31 st. CD was calculated as the deviation of the actual calving date from April 1st for the first calving season or October 1st for the second calving season. When more than one calving date was available from a dam, CI was calculated. Following previous studies we admitted CI records ranging from 290 days to 630 days (Goyache et al., 1995; Goyache and Gutiérrez, 2001). When the calculated CI was outside this range all the subsequent CI records from these dams were deleted. When a dam began its reproductive career in a given calving season, its corresponding CDs were calculated with respect to the reference date of this calving season regardless of the subsequent actual calving dates. When a dam calved outside the calving season but within the admitted CI range CD record was calculated with respect to the reference date of the calving season in the year in which calving was expected to happen. Animals showing ambiguous identification were removed from the database. Records of herds with less than six assessed animals in the data set were deleted to optimise computing resources. Finally, the analysed database included 5081 classification records, 10196 CD records, 2007 CI records and 2533 AFC records. Pedigree information of classified animals included 2425 additional animals. Thus, 8293 animals were involved in the estimation of genetic parameters. Artificial insemination is widely used in Asturiana de los Valles breed (Gutiérrez et al., 1997) generating close genetic connections between herds. Further description of the available databases can be found in Table 1 .

Genetic parameters were estimated via a multivariate REML procedure applied to a mixed linear model including the animal additive genetic effect (u) considered as a random variable $(u \sim N(0, A \sigma 2 u)$. Initial analysis showed that fitting a permanent environment effect did not have a statistically signifi- 
Table 1

Description of the available databases

\begin{tabular}{lcccc}
\hline & Type traits & Calving date & Calving interval & Age at first calving \\
\hline No. of records & 5081 & 10196 & 2007 & 2533 \\
No. of dams & 5081 & 5233 & 1574 & 2533 \\
No. of dams at first calving & 1863 & 2497 & 691 & 2533 \\
No. of progeny groups & 19 & 17 & 13 & 23 \\
No. of dams in progeny groups & 1027 & 673 & 650 & 963 \\
\hline
\end{tabular}

Progeny groups were defined as the number of Artificial Insemination sires having 20 or more daughters producing data.

cant contribution and was therefore dropped from the final model. All runs were carried out using the REML VCE 4.2.5 package (Groeneveld, 1998). The fitted model included the following as fixed effects: for type traits (Gutiérrez and Goyache, 2002): herd, classifier-year-season (considering the two seasons described above), stage of lactation of the dam at classification (lactating and dry), and age of the animal at classification (five levels: less than 2 years old, 3 years, 4 years, from 5 to 9 years old and older than 9 years). for reproductive traits: herd, year of calving, calving season, sex of calf and age of dam as a covariate.

\section{Results and discussion}

Means, standard deviations and heritabilities for type traits, CD, CI and AFC are presented in Table 2. Heritabilities of type traits are consistent with those previously reported for the same breed (Gutiérrez and Goyache, 2002), ranging between 0.03 (LL) and 0.33 (BC). Heritabilities of CI and AFC were 0.125 and 0.235 , respectively. These values are in close agreement with those previously reported for the same traits in the same breed of 0.12 and 0.27 , respectively, analysing a different database (Goyache and Gutiérrez, 2001). The heritability of CD was 0.21 . This parameter was estimated for the first time in the Asturiana de los Valles breed. According with literature (Koots et al., 1994a; Rust and Groeneveld, 2001), CD heritability was higher than for CI. Higher heritability estimates for CD (around 0.40) can be obtained if a penalty score for CD (computed by adding 21 days to the highest calving date value in a year) is given to those dams that did not calve during a particular year (Buddenberg et al., 1990; Van der Westhuizen et al., 2000). Nevertheless, in the present study a more restrictive approach was preferred.

Heritability estimates for $\mathrm{CI}$ and $\mathrm{AFC}$ in the present study are higher than those usually found in the literature. However, they are in close agreement with other estimations for these traits in the same breed (Goyache and Gutiérrez, 2001). Asturiana de los Valles breed had a high genetic variability for

Table 2

Description and heritabilities of reproductive and type traits analysed

\begin{tabular}{|c|c|c|c|c|c|c|c|}
\hline \multirow[t]{2}{*}{ Trait } & \multirow[t]{2}{*}{ Abbreviation } & \multicolumn{2}{|l|}{ Score } & \multirow[t]{2}{*}{ Mean } & \multirow[t]{2}{*}{ S.D. } & \multirow[t]{2}{*}{$h^{2}$} & \multirow[t]{2}{*}{ S.E. } \\
\hline & & 5 & 9 & & & & \\
\hline Breed characteristics & $\mathrm{BC}$ & Sufficient & Excellent & 7.43 & 0.93 & 0.334 & 0.015 \\
\hline Size & $\mathrm{S}$ & Small & Large & 7.28 & 0.74 & 0.301 & 0.019 \\
\hline Body depth & $\mathrm{BD}$ & Shallow & Deep & 7.54 & 0.63 & 0.204 & 0.017 \\
\hline Thigh development & $\mathrm{TD}$ & Thin & Muscled & 7.45 & 0.66 & 0.197 & 0.021 \\
\hline Legs line & LL & Odd & Regular & 7.45 & 0.68 & 0.032 & 0.009 \\
\hline Udder development & UD & Small & Large & 6.88 & 0.76 & 0.135 & 0.018 \\
\hline Final score & FS & & & 73.49 & 4.42 & 0.251 & 0.016 \\
\hline Calving date (days) & $\mathrm{CD}$ & & & 12.27 & 91.54 & 0.209 & 0.015 \\
\hline Calving interval (days) & $\mathrm{CI}$ & & & 488.03 & 177.81 & 0.125 & 0.020 \\
\hline Age at first calving (days) & $\mathrm{AFC}$ & & & 1063.48 & 223.91 & 0.235 & 0.018 \\
\hline
\end{tabular}


most productive and reproductive traits we analysed (Gutiérrez et al., 1997; Goyache and Gutiérrez, 2001, Goyache et al., 2002). In their review of the literature, Koots et al. (1994a) calculated an average heritability for CI from four published papers of 0.01 and 0.06 for multiparous cows and heifers, respectively. The same authors calculated average heritabilities of 0.06 for AFC (from seven estimates) and 0.08 for $\mathrm{CD}$ (from ten estimates). Bourdon and Brinks (1983) estimated an AFC heritability of 0.07; Pryce et al. (2000) calculated a CI heritability of 0.022 in British Holstein; Dadati et al. (1986), 0.04 in Canadian Holstein; López de Torre and Brinks (1990) obtained heritabilities of 0.02 for CI and 0.16 for CD in Retinta cattle; Haile-Mariam and KassaMersha (1994) obtained heritabilities of 0.04 and 0.07 for AFC and CI, respectively, in Boran cattle exploited in tropical conditions; Braga Lôbo (1998) estimated a heritability of $0.14 \pm 0.01$ and $0.29 \pm 0.09$ for CI and AFC, respectively, in zebu cows. Tonhati et al. (2000) calculated heritabilities of 0.10 and 0.20 for the same traits in Brazilian buffaloes.

Table 3 shows the genetic correlations between reproductive and type traits. The genetic correlations between reproductive traits were moderate and have the same sign as phenotypically observable patterns (Bourdon and Brinks, 1983; MacGregor and Casey, 1999): negative between CD and CI $(-0.285)$ and between $\mathrm{CD}$ and $\mathrm{AFC}(-0.085)$, and positive between CI and AFC (0.233). Dams calving earlier tend to lengthen the subsequent CI. Michaux et al. (1987) reported that a delay in first calving lengthens subsequent CIs. The genetic correlation between CD and CI, and between CD and AFC were of the same sign as reported by Koots et al. (1994b) in their review of the literature. López de Torre and Brinks (1990) found a genetic correlation between CD and CI of 0.06. However, when CI was adjusted for the time that bulls were not available to the cow, these authors found genetic correlations with $\mathrm{CD}$ from 0.20 to 0.25 . Estimates of genetic correlation between $\mathrm{AFC}$ and $\mathrm{CI}$ found in the literature are: frequently negative ranging from -0.056 (HaileMariam and Kassa-Mersha, 1994), to -0.22 (Tonhati et al., 2000). These latter estimates were obtained in very rigorous management conditions. A environmental influence on these estimations cannot be discarded. Less developed heifers at first calving would tend to have more problems to begin cycling the subsequent mating period. Braga Lôbo (1998) found a high positive phenotypic correlation between $\mathrm{AFC}$ and CI (0.43), while genetic correlation was low positive (0.10). In our context, AFC appears to be a crucial trait in the reproductive life of the dam. Selection for a shorter AFC would lead to an improvement of CI performance without affecting $\mathrm{CD}$ to a greater extent.

Genetic correlations between reproductive and type traits ranged from -0.297 to 0.447 . The genetic correlations between LL and reproductive traits are no different from zero. This can be associated to the very low heritability of LL. The three reproductive traits considered present large differences in their genetic relationship with type traits. In general, CD exhibits very low genetic correlations with type traits, presenting estimates close to zero. However, the genetic correlation between $\mathrm{CD}$ and S, BD, UD and FS seems to be favourable; thus, a good type classification would lead to early calvings. The genetic correlations between CI and type traits are moderate and lower (more favourable) than those obtained for CD, except for UD. Genetic correlations between $\mathrm{CI}$ and BC, S and FS are lower than -0.20 . CI would be a better candidate trait than $\mathrm{CD}$ to build an index including reproductive regularity and type traits. However, our results may be affected by

Table 3

Genetic correlations and standard errors (below) between calving date, calving interval, age at first calving and type traits

\begin{tabular}{|c|c|c|c|c|c|c|c|c|c|}
\hline & $\mathrm{CI}$ & AFC & $\mathrm{BC}$ & S & $\mathrm{BD}$ & $\mathrm{TD}$ & LL & UD & FS \\
\hline \multirow[t]{2}{*}{$\mathrm{CD}$} & -0.285 & -0.085 & -0.023 & -0.096 & -0.072 & 0.000 & -0.001 & -0.125 & -0.111 \\
\hline & 0.049 & 0.024 & 0.026 & 0.031 & 0.031 & 0.034 & 0.081 & 0.050 & 0.023 \\
\hline \multirow[t]{2}{*}{ CI } & & 0.233 & -0.297 & -0.206 & -0.165 & -0.027 & -0.072 & -0.068 & -0.287 \\
\hline & & 0.078 & 0.056 & 0.060 & 0.080 & 0.086 & 0.155 & 0.052 & 0.084 \\
\hline \multirow[t]{2}{*}{$\mathrm{AFC}$} & & & 0.238 & 0.080 & 0.445 & 0.447 & 0.100 & -0.142 & 0.399 \\
\hline & & & 0.032 & 0.040 & 0.051 & 0.067 & 0.134 & 0.064 & 0.042 \\
\hline
\end{tabular}


farmers' selection. This possibility has been highlighted before in dairy cattle (Pryce et al., 2000). CI needs at least two calving dates to calculate a single score. Cows with regular reproductive performance have more opportunities to stay on farms. It may be that farmers select animals with the best conformation amongst those showing the better reproductive performance. Thus, CI data could have been obtained mostly from well-conformed/regular dams. Pryce et al. (2000), commenting on this topic in Holstein cattle suggest that farmers' selection would only be likely to affect phenotypic correlations. However, it has been shown that selection not only produces changes in the genetic variance of the trait directly selected, but genetic variances of and covariances between other correlated traits can be also affected (Villanueva and Kennedy, 1990; Phocas and Colleau, 1996). Nevertheless, available databases included a substantial proportion of first calver cows. The structure of our data suggests (see Table 1) that the possible bias of our results, if being, does not seem to be substantial and can be compared with those affecting other scientific papers (Pryce et al., 2000).

CD scores were obtained from a larger sample of dams, including discarded dams' performance. It is likely that the genetic correlations found between type traits and CD are less affected by management practices. Differences found in genetic correlations between BC and CD $(-0.023)$ and CI $(-0.297)$ can support this line of thought. $\mathrm{BC}$ is, in fact, an index that scores the animal's conformity to the breed standard. Virtually, BC is not genetically correlated with $\mathrm{CD}$, whereas it does present a moderate and favourable genetic correlation with CI. Since the preservation of breed characteristics is an important goal for Asturiana de los Valles breeders (Goyache and Gutiérrez, 2001), an important selective pressure for this trait and other conformation traits cannot be discarded.

In contrast with $\mathrm{CD}$ and $\mathrm{CI}, \mathrm{AFC}$ presents the highest genetic correlations with type traits. Except for UD, a good type classification would lead to a delay in AFC. Genetic correlations between AFC and most type traits are positive and higher than 0.2 (BC) and 0.3 (BD, TD and FS). In accordance with these results, the deeper-well muscled heifers would have the larger AFCs. Shorter AFC affects dams' size and development. Thus, the older animals at first calving would present higher skeletal and muscular development (BD, TD), producing a good general aspect of the female (BC) and leading to better type classifications.

There are not many references with respect to the relationships between type traits and reproductive performance. Pryce et al. (2000) obtained unfavourable genetic correlations between CI and Stature and Body Depth of 0.33 and 0.26, respectively, in British Holstein. Thus, taller and deeper cows would have a longer CI. These authors do not discard the possibility of the existence of a more favourable treatment of farmers to taller and deeper cows, giving them more opportunities to conceive. In Asturiana de los Valles cattle, animals showing the best skeletal development (S, BD) would have shorter CI and early $\mathrm{CD}$. The Asturiana de los Valles breed is exploited mostly in mountain and semi-extensive conditions (Goyache et al., 1995, 2000). The 'larger' animals could be in better position to compete with other animals for limited food. Dadati et al. (1986) found that chest floor and capacity (subjectively assessed) were favourably related to CI in Canadian Holsteins. Hence, 'stronger' cows would have a shorter CI.

UD presents negative (favourable) genetic correlations with the three considered reproductive traits ranging from $-0.068 \pm 0.052$ for CI to $-0.142 \pm 0.064$ for AFC. Dadati et al. (1986) found a genetic correlation in Canadian Holstein between the Mammary system and CI of -0.26 . Other udder traits analysed by these authors also demonstrated a favourable genetic correlation with CI. However, Dairy character and Dairyness presented unfavourable genetic correlations with CI of 0.38 and 0.43 respectively. Dadati et al. (1986) assumed that these genetic correlations were primarily influenced by milk production. Dairy character and Dairyness would be highly genetically correlated with milk production and longer open periods, while higher scores for udder traits would be associated with shorter CI. Higher producing cows exhibiting lower udder traits scores would have longer CI. Pryce et al. (2000) found a genetic correlation between CI and udder depth of -0.13 in British Holstein. In the current analysis, UD scores the udder size at classification. This would be expected to be associated with a higher milk production. Cows with more developed and deeper udders are supposed to calve earlier for a 
first time and to maintain this trend in subsequent calvings. The results obtained in the present paper suggest the possibility of testing a possible genetic relationship between reproductive traits and the maternal component of preweaning growth traits.

\section{Conclusions}

The genetic variability found in general for the analysed reproductive traits would justify the inclusion of some measure of fertility in the beef cattle breeding objective. Although the analysed data was not obtained from a management system presenting absolutely restricted breeding seasons, CD presented larger genetic variability than CI. In addition, CD exhibited favourable genetic correlations with major growth traits, is a less biased trait and exhibits less phenotypic variability than CI. CD would hence be a more interesting trait than $\mathrm{CI}$ to include in a breeding objective, as highlighted in the literature (Bourdon and Brinks, 1983; Buddenberg et al., 1990; López de Torre and Brinks, 1990; Marshall et al., 1990; MacGregor and Casey, 1999; Van der Westhuizen et al., 2000). Moreover, CI is only available after the cow has calved for a second time. This limits its use in selective breeding, which requires early information. There might exist a strong selection for CI because the least fertile cows do not have much opportunity to calve for a second time (Pryce et al., 2000). CD might be a more realistic measure of the reproductive performance of the whole population.

Moreover, $\mathrm{CD}$, in contrast with $\mathrm{CI}$, presents an unfavourable genetic correlation with AFC. AFC is a determinant trait in the female's reproductive career (Michaux et al., 1987). AFC has the largest heritability of the reproductive traits analysed. AFC has a favourable correlation with major growth traits in beef cattle (Bourdon and Brinks, 1983), as does CD (Koots et al., 1994b).

Type traits, especially UD, FS and traits scoring skeletal development (S and BD), are favourably genetically correlated with CI. However, type traits and $\mathrm{CD}$ appear to be genetically independent and AFC presents a non-favourable genetic correlation with reproductive traits. Our results suggest that the possibility of using type classification to construct an index to improve reproductive performance is little. The more reliable possibility to build a possible selection index comprising type classification and reproductive performance would be based on AFC. Type classification at first calving could help to increase the information to select dams to stay on the farm in subsequent calvings on the basis of their expected performance.

However, a linear classification system would be expected to be more useful than the current one (Gutiérrez and Goyache, 2002). The analysed traits score the deviation (positive or negative) from an 'optimum', measuring less phenotypic and genetic variation. Traits at the extremes of the observed biological (anatomical) variability could show the same low score, thus inducing a loss of biological relationships between traits (Vukasinovic et al., 1997). The genetic correlations between type traits and CI estimated in this paper are, in general, lower than those obtained using a linear classification system (Pryce et al., 2000). Taking all this into account, the re-consideration of the type classification system used in the Asturiana de los Valles beef cattle breed, advocating the implementation of a linear-type traits assessment system, could be recommended (Goyache et al., 2001).

\section{Acknowledgements}

This paper was partially funded by a grant from CICYT-FEDER, no. 1FD97-1633, and the Principado de Asturias Regional Government through the Consejería de Medio Rural y Pesca. The authors would like to thank J.L. Riesgo, E. Fernández, A. Menéndez, J.A. Vázquez and the other ASEAVA staff members for their kind support.

\section{References}

Braga Lôbo, R.N., 1998. Genetic parameters for reproductive traits of zebu cows in the semi-arid region of Brazil. Livest. Prod. Sci. 55, 245-248.

Bourdon, R.M., Brinks, J.S., 1983. Genetic, environmental and phenotypic relationships among gestation length, birth weight, growth traits and age at first calving in beef cattle. J. Anim. Sci. 55, 543-553.

Brotherstone, S., 1994. Genetic and phenotypic correlation between linear type traits and production traits in HolsteinFriesian dairy cattle. Anim. Prod. 59, 183-187.

Buddenberg, B.J., Brown, C.J., Brown, A.H., 1990. Heritability 
estimates of calving date in Hereford cattle maintained on range under natural mating. J. Anim. Sci. 68, 70.

Dadati, E., Kennedy, B.W., Burside, E.B., 1986. Relationships between conformation and calving interval in Holstein cows. J. Dairy Sci. 69, 3112-3119.

Freeman, A.E., 1984. Secondary traits: Sire valuation and the reproductive complex. J. Dairy Sci. 67, 449-458.

Goyache, F., Gutiérrez, J.P., 2001. Heritability of reproductive traits in Asturiana de los Valles beef cattle breed. Arch. Tierz. 44, 489-496.

Goyache, F., Gutiérrez, J.P., Dunner, S., Cañón, J., 1995. Principales efectos ambientales que influyen sobre el intervalo entre partos de la raza Asturiana de los Valles. Arch. Zootec. 44, 317-334.

Goyache, F., Gutiérrez, J.P., Fernández, I., Villa, A., Alvarez, I., Rodríguez Castañón, A.A., García Paloma, J.A., 2000. Efectos ambientales que influyen en la dificultad de partos y el peso al nacimiento en la raza asturiana de los valles. Arch. Zootec. 49, 481-492.

Goyache, F., del Coz, J.J., Quevedo, J.R., López, S., Alonso, J., Ranilla, J., Luaces, O., Alvarez, I., Bahamonde, A., 2001. Using artificial intelligence to design and implement a morphological assessment system in beef cattle. Anim. Sci. 73, 49-60.

Goyache, F., Royo, L.J., Alvarez, I., Gutiérrez, J.P., 2002. Testing a continuous variation in preweaning expression of muscular hypertrophy in beef cattle using field data. Arch. Tierz. 45, 139-150.

Groeneveld, E., 1998. VCE4 Version 4.2.5. User's Guide and Reference Manual. Marience, Germany.

Gutiérrez, J.P., Goyache, F., 2002. Estimation of genetic parameters of type traits in beef cattle. J. Anim. Breed. Genet. 119, 93-100.

Gutiérrez, J.P., Cañón, J., Goyache, F., 1997. Estimation of direct and maternal genetic parameters for preweaning traits in the Asturiana de los Valles beef cattle breed through animal and sire models. J. Anim. Breed. Genet. 114, 261-266.

Haile-Mariam, H., Kassa-Mersha, H., 1994. Genetic and environmental effects on age at first calving and calving interval of naturally bred Boran (zebu) cows in Ethiopia. Anim. Prod. 58, 329-334.

Koots, K.R., Gibson, J.P., Smith, C., Wilton, J.W., 1994a. Analyses of published genetic parameter estimates for beef production traits. 1. Heritability. Anim. Breed. Abstr. 62, 309-338.

Koots, K.R., Gibson, J.P., Smith, C., Wilton, J.W., 1994b. Analyses of published genetic parameter estimates for beef production traits. 2. Phenotypic and genetic correlations. Anim. Breed. Abstr. 62, 825-853.

Larroque, H., Ducrocq, V., 1999. An indirect approach for the estimation of genetic correlations between longevity and other traits. In: Fourth International Workshop on Genetic Improvement of Functional Traits in Cattle: Longevity, Jouy en Josas, 9-11 May 1999. Interbull Bulletin, Vol. no. 20. Interbull, Uppsala, Sweden, pp. 128-135.

López de Torre, G., Brinks, J.S., 1990. Some alternatives to calving date and interval as measures of fertility in beef cattle. J. Anim. Sci. 68, 2650-2657.

MacGregor, R.G., Casey, N.H., 1999. Evaluation of calving interval and calving date as measures of reproductive performance in a beef breed. Livest. Prod. Sci. 57, 181-191.

MacNeil, M.D., Newman, S., Enns, R.M., Stewart-Smith, J., 1994. Relative economic values for Canadian beef production using specialized sire and dam lines. Can. J. Anim. Sci. 74, 411-417.

Marshall, D.M., Minqiang, W., Freking, B.A., 1990. Relative calving date of first-calf heifers as related to production efficiency and subsequent reproductive performance. J. Anim. Sci. 68, 1812.

Meyer, K., Brotherstone, S., Hill, W.G., Edwards, M.R., 1987. Inheritance of linear type traits in dairy cattle and correlations with milk production. Anim. Prod. 44, 1-10.

Meyer, K., Hammond, K., Parnell, P.F., Mackinnon, M.J., Sivarajasingam, S., 1990. Estimates of heritability and repeatability for reproductive traits in Australian beef cattle. Livest. Prod. Sci. 25, 15-30.

Michaux, C., Detal, G., Hanset, R., 1987. Age aux vêlages, intervalles de vêlages et taux de renouvellements à l'intérieur de troupeaux Blanc-Bleu Belge de type viandeux. Ann. Méd. Vét. 131, 553-570.

Newman, S., Morris, C.A., Baker, R.L., Nicoll, G.B., 1992. Genetic improvement of beef cattle in New Zealand: breeding objectives. Livest. Prod. Sci. 32, 111-130.

Phocas, F., Bloch, C., Chapelle, P., Bécherel, F., Renand, G., Menissier, F., 1998. Developing a breeding objective for a French purebred beef cattle selection program. Livest. Prod. Sci. 57, 49-65.

Phocas, F., Colleau, J.J., 1996. Genetic steady state under BLUP selection for an infinite and homogeneous population with discrete generations. Theor. Appl. Genet. 93, 287-294.

Ponzoni, R.W., 1992. Which trait for genetic improvement of beef cattle reproduction: calving rate or calving day? J. Anim. Breed. Genet. 109, 119-128.

Pryce, J.E., Coffey, M.P., Brotherstone, S., 2000. The genetic relationship between calving interval, body condition score and linear type and management traits in registered Holsteins. J. Dairy Sci. 83, 2664-2671.

Rege, J.E.O., Famula, T.R., 1993. Factors affecting calving date and its relationship with production traits of Hereford dams. Anim. Prod. 57, 385.

Rust, T., Groeneveld, E., 2001. Variance component estimation on female fertility traits in beef cattle. S. Afr. J. Anim. Sci. 31, 131-141.

Tonhati, H., Vascocellos, F.B., Alburquerque, L.G., 2000. Genetic aspects of productive and reproductive traits in a Murrah buffalo herd in São Paulo, Brazil. J. Anim. Breed. Genet. 117, 331-339.

Van der Westhuizen, R.R., Schoeman, S.J., Jordaan, G.F., van Wyck, J.B., 2000. Heritabilities of reproductive traits in a beef cattle herd using a multitraits analysis. S. Afr. J. Anim. Sci. 30 (Suppl. 1), 140-141.

Villanueva, B., Kennedy, W., 1990. Effect of selection on genetic parameters of correlated traits. Theor. Apppl. Genet. 80, 746752.

Vukasinovic, N., Moll, J., Künzi, N., 1997. Factor analysis for evaluating relationships between herd's life and type traits in Swiss Brown cattle. Livest. Prod. Sci. 49, 227-234. 